IOSR Journal of Pharmacy

e-ISSN: 2250-3013, p-ISSN: 2319-4219, www.iosrphr.org

Vol. 2, Issue 6, Nov-Dec. 2012, PP. 45-51

\title{
Validated HPTLC method for quantitation of Hexetidine in bulk drug and in Mouth Wash formulation
}

\author{
Safeena Sheikh, Suhail Asghar, Showkat Ahmad \\ Unijules Life Sciences Ltd, B - 35, 36 MIDC Area Kalmeshwar, Nagpur - 441501 (Maharashtra) India
}

\begin{abstract}
A new, simple, precise, and accurate HPTLC method for quantitation of hexetidine as the bulk drug and in mouth wash formulation have been developed. Chromatographic separation of the drug was performed on aluminium backed plates coated with silica gel $60 \mathrm{~F} 254$ as the stationary phase and the solvent system consisted of Toluene: Methanol $(8: 2 \mathrm{v} / \mathrm{v})$. Densitometric evaluation of the separated zones was performed at $525 \mathrm{~nm}$. The drug was satisfactorily resolved with the formulation excipients with Rf values of 0.30 respectively. The accuracy and reliability of the method was assessed by evaluation of linearity which found in the range of 1 to $6 \mu \mathrm{g} / \mathrm{spot}$ with the correlation coefficient of 0.999 , precision intra-day 0.86 to $1.03 \%$ and inter day 0.25 to $0.34 \%$ and accuracy afford $98-102 \%$, and specificity in accordance with ICH guidelines.
\end{abstract}

Key words: - Hexetidine, method development, validation, stability, densitometry, Quantification.

\section{INTRODUCTION}

Hexetidine is an antiseptic. It kills bacteria and fungi and is therefore used to treat minor mouth infections, including oral thrush. It can be used as a mouth wash or to gargle with.

Hexetidine contains is 1, 3-bis (2-ethylhexyl)]-5-methylhexahydropyrimidin-5-amine. An oily liquid, colorless or slightly yellow, very slightly soluble in water, very soluble in acetone, in alcohol and in methylene chloride. It dissolves in dilute mineral acids.<smiles>CCCCC(CC)CN1CN(CC(CC)CCC)CC(C)(N)C1</smiles>

Figure.1: Chemical structure of hexetidine

II. MATERIAL AND METHODS

Chemical, Equipments and Instrument:-

All chemicals and reagents of analytical grade were purchased from Merck chemical, Mumbai. India. Pure drug sample of Hexetidine was kindly supplied as a sample from Alfa Aesar, and $0.1 \%$ w/v mouth wash was formulated. HPTLC system used for analysis Camag HPTLC system. The sample were spotted in the form of bands with a Camag 100 microlite sample syringe (Hamilton, Bondouz, Switzerland) on Precoated silica gel aluminium plate $60 \mathrm{~F}_{254}(20 \mathrm{X} 10)$ with $250 \mu \mathrm{m}$ thickness;(Merck") using a Camag Linomat 5 sample applicator (Switzerland).The linear ascending development was carried out in $20 \mathrm{~cm} \mathrm{X} 10 \mathrm{~cm}$ twin trough chamber using mobile phase (Toluene: Methanol 8:2 v/v). TLC plates were dried on Camag TLC plate heater III.Densitometric scanning was performed on Camag TLC scanner 3 in the reflectance-absorbance mode at $525 \mathrm{~nm}$ after derivatization with ninhydrin solution for all measurement and operated by Camag WINCATS software. The source of radiation utilized was deuterium lamp emitting a continuous UV spectrum 200 to 400.

\section{Preparation of standard solution:}

Weigh accurately hexetidine $10.0 \mathrm{mg}$ in $50.0 \mathrm{ml}$ volumetric flask and dissolve the content in $30.0 \mathrm{ml}$ methanol mix the content and make up the volume to $50 \mathrm{ml}$ with methanol. 


\section{Sample preparation:}

Transfer accurately $10.0 \mathrm{ml}$ test sample in $50 \mathrm{ml}$ volumetric flask and dissolved in methanol $30.0 \mathrm{ml}$ volumetric flask and make up the volume to $50 \mathrm{ml}$.

\section{Optimization of the HPTLC method:}

Chromatographic separation studies were carried out on the stock solution of hexetidine. Initially on the plate $10 \mu \mathrm{l}$ of stock solution was applied as band $8 \mathrm{~mm}$ of width. Plates were developed by ascending development using neat solvents like toluene, methanol, chloroform, dichloromethane, ethyl acetate, acetone, Acetonitrile etc. without chamber saturation. Based on the results of these initial chromatograms binary and ternary mixtures of solvents were tried to achieve optimum resolution between hexetidine. After several trials mixture of Toluene: Methanol $(8: 2 \mathrm{v} / \mathrm{v})$ was chosen for as the mobile phase for analysis then the plate was derivatized with ninhydrin solution and dried at $110^{\circ} \mathrm{C}$ for 5 minute. The other chromatographic conditions like chamber saturation time, run length, sample application rate and volume, sample application positions, distance between tracks, detection wavelength, were optimized to give reproducible Rf value, better resolution, and symmetrical peak shape for the drugs. The spot appeared more compact and peak shape more symmetrical when the TLC plate were pretreated first with methanol and then with the mixture of chloroform and methanol $(1: 1 \mathrm{v} / \mathrm{v})$ after that the plate was activated at $110^{\circ} \mathrm{C}$ for 5 minutes.

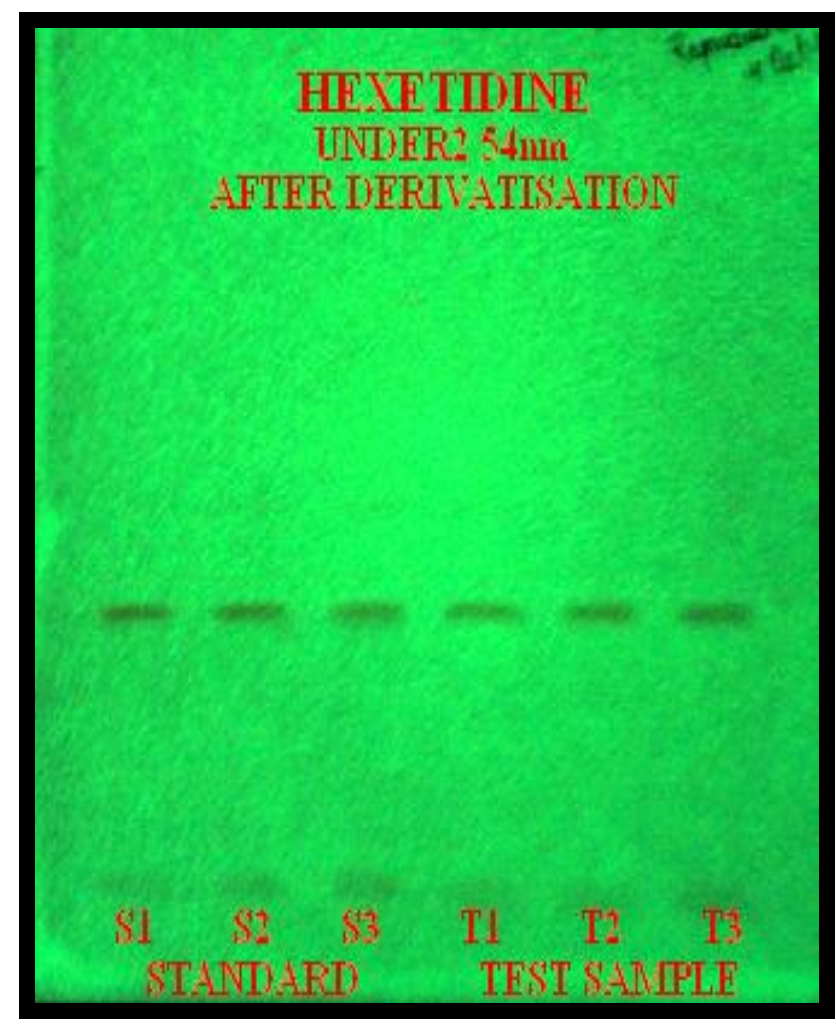

Figure2:- chromatogram shows the separated spots of hexetidine in standard and in test sample. 


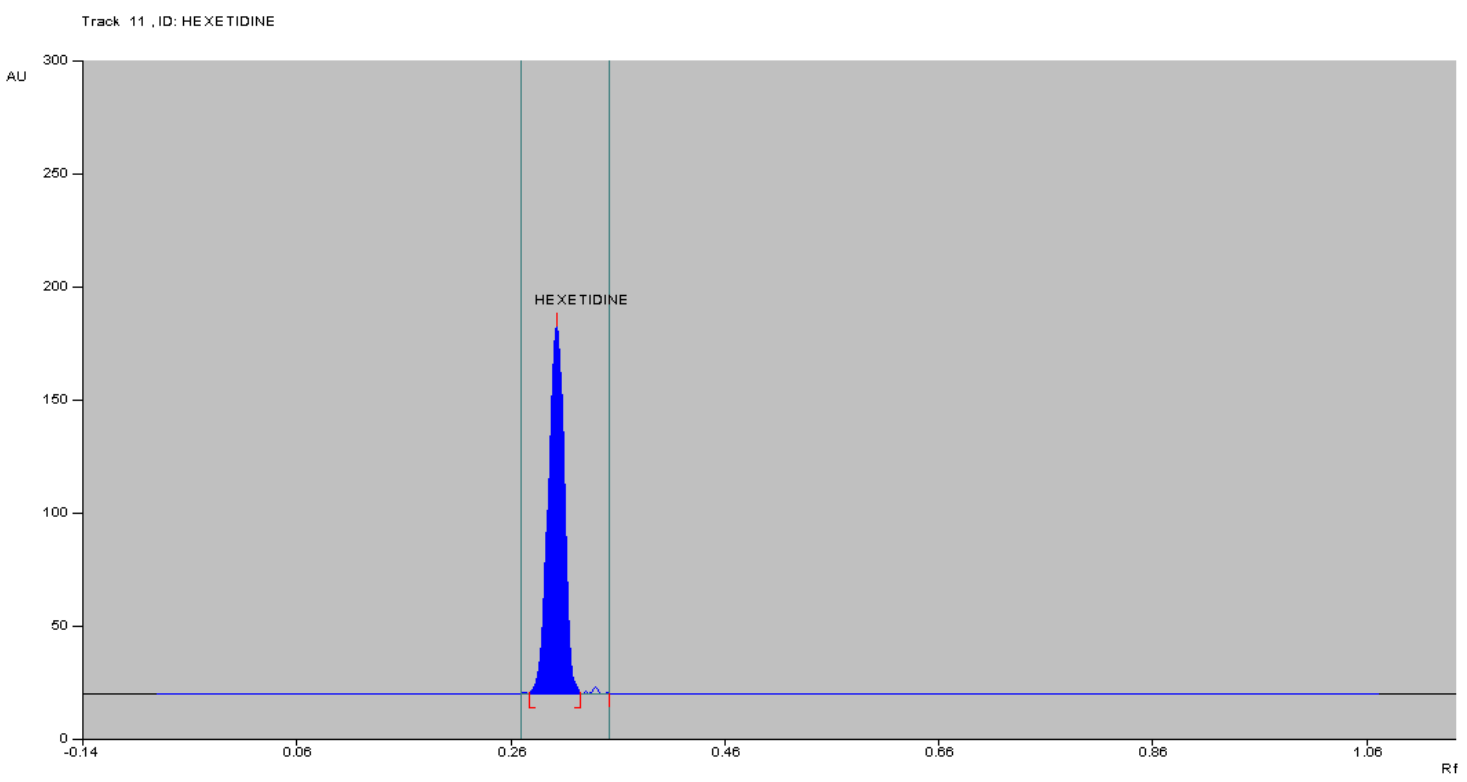

Figure 3:- Densitogram of Standard Hexetidine $(\mathrm{Rf}=0.30)$.

\section{Linearity and Range:}

\section{VALIDATION OF THE METHOD}

Stock standard solution was prepared by dissolving $10.0 \mathrm{mg}$ of hexetidine in $10.0 \mathrm{ml}$ of methanol. The application volume on the Linomat set to get the final concentration of 1.0 to $6.0 \mu \mathrm{g} / \mathrm{spot}$. The plates were developed on previously described mobile phase. Peak areas were plotted against corresponding concentration to obtain the calibration graphs (Figure 4).

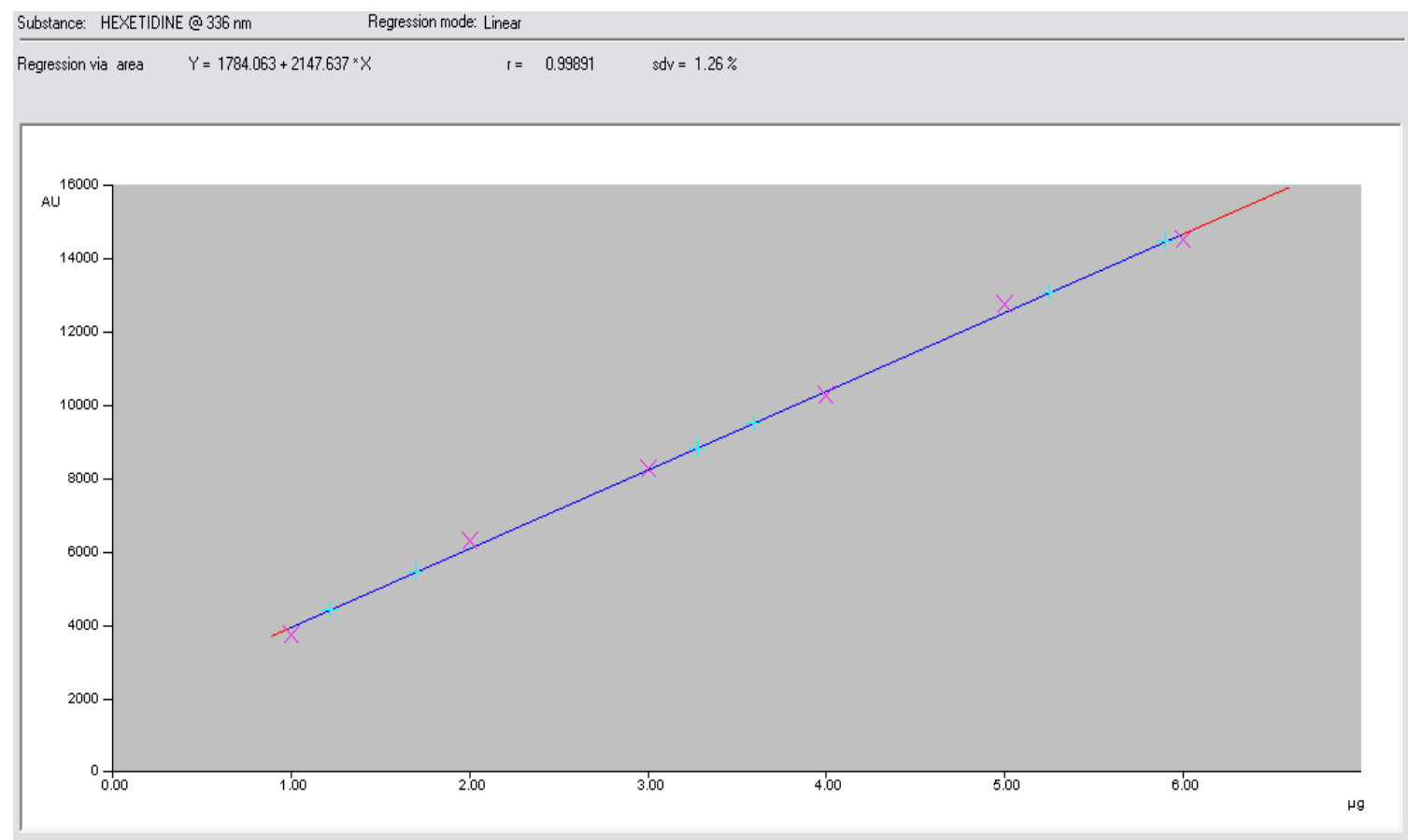

Figure 4:- Showing calibration curve, correlation coefficient and standard deviation.

\section{Precision:}

Three sets of three different concentration standard solution $(2.0,4.0,6.0 \mu \mathrm{g} / \mu \mathrm{l})$ was prepared. The intra day and inter day precision of the developed TLC method was determined by preparing the samples of the same batch in nine determinations with three concentrations and three replicate each on the same day. The inter-day precision was also determined by assaying the sample in triplicate per day for consecutive three days. 


\section{Limit of detection (LOD) and Limit of Quantification (LOQ)}

For the evaluation of limit of detection and limit of quantification different concentrations of standard solution were applied along with methanol as blank and determined on the basis of signal to noise ratio.

$$
\text { Track B, ID: Standard3 }
$$

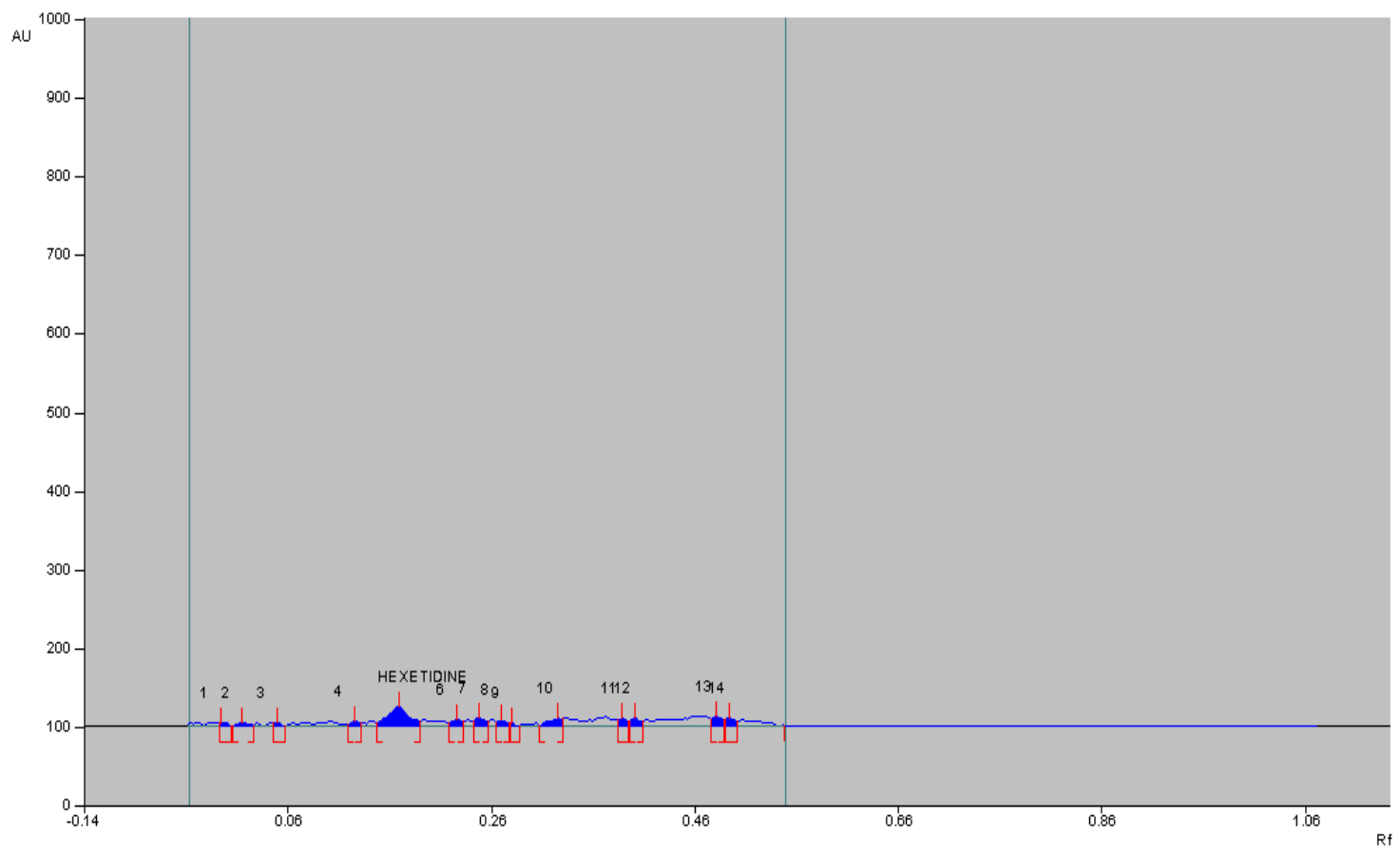

Figure 5:- Showing noise response.

\section{Robustness of the Method}

By introducing small changes in the mobile phase composition, the effects on the result were examined. Mobile phases having different composition like Toluene: methanol (8.1:1.9v/v), (8.3:1.7 v/v); $(7.9: 2.1 \mathrm{v} / \mathrm{v}) ;(7.8: 2.2 \mathrm{v} / \mathrm{v})$ were tried and chromatograms were run. The plates were prewashed by Chloroform: methanol $(1: 1)$ mixture and then with methanol and activated at $110^{\circ} \mathrm{C}$ for $5,10,15$ min respectively prior to chromatography. Time from spotting to chromatography and from chromatography to scanning was varied from $0,20,40$ and 60 minutes. In this also detection wavelength is altered, duration of saturation (+/-5min) development distance $(+/-1 \mathrm{~cm})$ changes. Robustness of the method was found satisfactorily.

\section{Specificity}

Specificity of the method was determined by analyzing the standard drug and test samples. The spot for hexetidine in the sample was confirmed by comparing the Rf and spectrum of the spot to that of a standard. The peak purity of hexetidine was determined by comparing the spectral spectrum (figure 6a). The placebo was not interfering with the actives (figure 6b). 


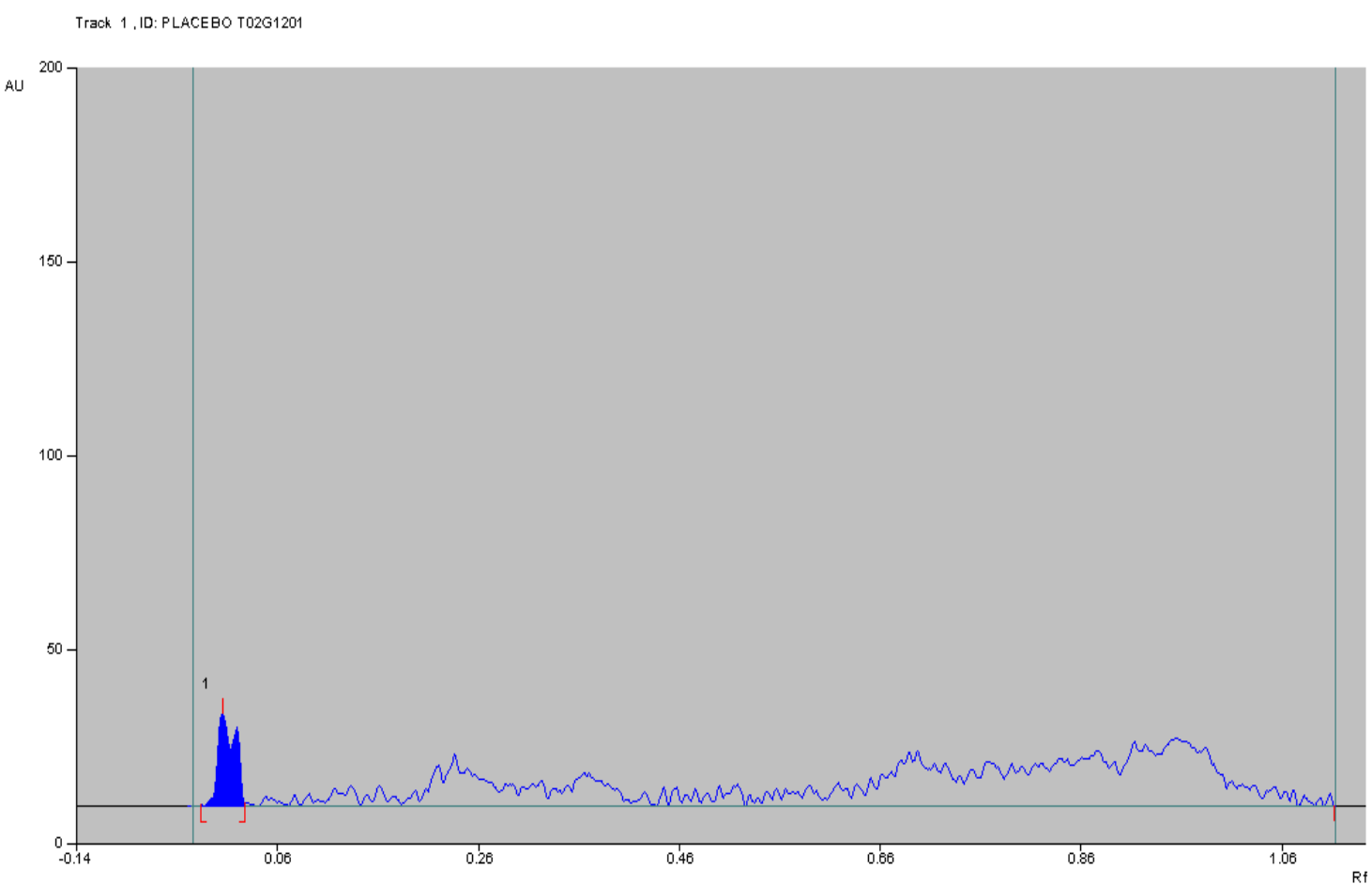

Figure 6(a):- Showing densitogram of placebo.

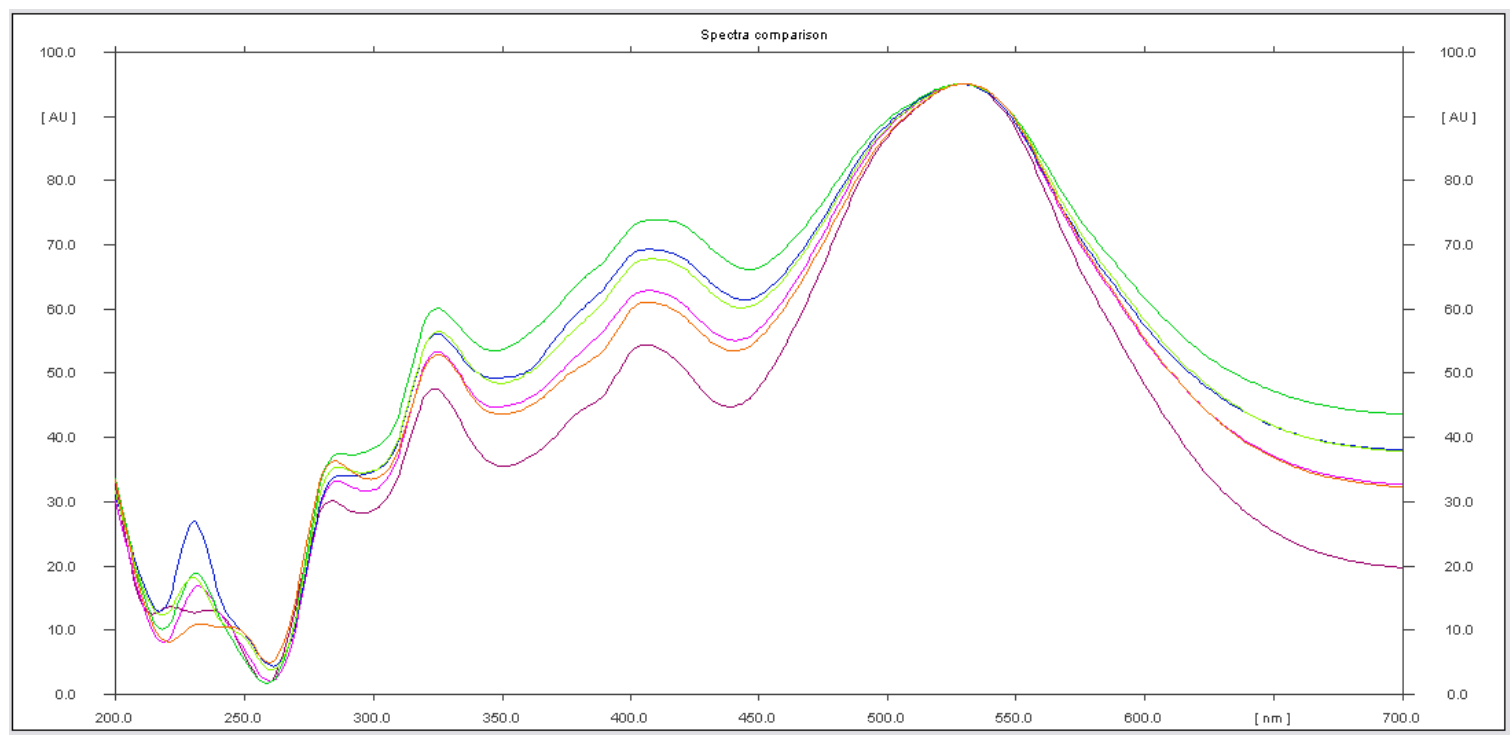

Figure 6(b):- The spectrum is showing that the separated spot at $\mathrm{Rf}=0.30$ was of pure hexetidine.

\section{Accuracy}

The accuracy of the method was carried out by applying the method to drug and it $0.1 \%$ mouth wash to which known amount of hexetidine standard corresponding to 80,100 and $120 \%$ of label claim had been loaded (standard addition method), on the placebo and analyzed by running chromatograms in optimized mobile phase.

\section{Analysis of Formulation}

Quantity of the formulation equivalent to $10 \mathrm{mg}$ of hexetidine was weighed and transferred to $50.0 \mathrm{ml}$ volumetric flask containing about $30 \mathrm{ml}$ of the methanol, mixed by shaking, and volume was made up to $50.0 \mathrm{ml}$ with same solvent, the sample solution was applied keeping appropriate distance between spots.

\section{RESULT \& DISCUSSION}

The HPTLC methods are significant methods for the quality assurance of drug molecules. HPTLC has emerged as a routine technique due to its advantages of low operating costs, high sample out put and the need 
for the minimum sample preparation. The major advantage of HPTLC is that the several samples can be run simultaneously using a small quantity of mobile phase unlike LC thus reducing the analysis time and cost per analysis. Hence, the method was developed for hexetidine bulk drug and in pharmaceutical formulation. The method was validated and found to be suitable for routine analysis of the selected drug and its formulation. The results of developed method and validation for the hexetidine in the current study were discussed below.

\section{Linearity}

The drug response was linear, regression correlation coefficient was found to be 0.999 over the concentration range $1-6 \mu \mathrm{g} /$ spot.

\section{Precision}

The results of the repeatability and intermediate precision experiment are shown in Table I. The developed method was found to be precise as the RSD values for repeatability and intermediate precision studies were $<2.0 \%$, respectively as recommended by $\mathrm{ICH}$.

Table I: - Precision Data.

\begin{tabular}{|c|c|c|c|c|c|}
\hline \multicolumn{3}{|c|}{ Repeatability Data } & \multicolumn{3}{|c|}{ Intermediate Precision } \\
\hline $\begin{array}{c}\text { Actual } \\
\text { Concentration } \\
(\mu \mathrm{g} / \mu \mathrm{l})\end{array}$ & $\begin{array}{c}\text { Concentration } \\
\text { obtained }(\mu \mathrm{g} / \mu \mathrm{l})\end{array}$ & \% RSD & $\begin{array}{c}\text { Actual } \\
\text { Concentration } \\
(\mu \mathrm{g} / \mu \mathrm{l})\end{array}$ & $\begin{array}{c}\text { Concentration } \\
\text { obtained }(\mu \mathrm{g} / \mu \mathrm{l})\end{array}$ & $\begin{array}{c}\% \\
\text { RSD }\end{array}$ \\
\hline 2 & 2.02 & \multirow{3}{*}{0.862} & 2 & 1.99 & \multirow{3}{*}{0.289} \\
\hline 2 & 2.02 & & 2 & 1.99 & \\
\hline 2 & 1.99 & & 2 & 2.00 & \\
\hline 4 & 4.05 & \multirow{3}{*}{1.037} & 4 & 4.01 & \multirow{3}{*}{0.250} \\
\hline 4 & 4.03 & & 4 & 4.00 & \\
\hline 4 & 3.97 & & 4 & 3.99 & \\
\hline 6 & 5.99 & \multirow{3}{*}{0.912} & 6 & 5.99 & \multirow{3}{*}{0.347} \\
\hline 6 & 6.05 & & 6 & 5.98 & \\
\hline 6 & 6.10 & & 6 & 6.02 & \\
\hline
\end{tabular}

\section{LOD and LOQ}

The LOD and LOQ were found to be $150 \mathrm{ngspot}^{-1}$ and $250 \mathrm{ngspot}^{-1}$ respectively.

Table II: - Robustness

\begin{tabular}{|l|c|c|}
\hline \multicolumn{1}{|c|}{ Parameter } & SD of peak area & \% RSD \\
\hline Mobile phase composition & 20.10 & 0.58 \\
\hline Amount of mobile phase & 48.54 & 1.38 \\
\hline Time from spotting to chromatography & 10.58 & 0.30 \\
\hline Time from chromatography to scanning & 48.15 & 1.35 \\
\hline Plate pretreatment & 16.84 & 0.47 \\
\hline Measurement wavelength (nm) & 54.81 & 1.52 \\
\hline Development distance & 21.04 & 0.57 \\
\hline Saturation time & 12.50 & 0.34 \\
\hline
\end{tabular}

The standard deviation of the peak areas was calculated for each parameter and the \% RSD was found to be less than $2 \%$. The low values of the \% RSD, as shown in Table II indicated robustness of the method.

\section{Recovery Studies}

Chromatogram was developed and the peak areas were noted. At each levels of the amount, three determinations were performed. As shown from the data in Table III good recoveries of the hexetidine in the range from 99.8 to 100.7 were obtained at various added concentration. 
Table III: - Recovery Data

\begin{tabular}{|l|l|l|l|l|l|}
\hline Drug & $\begin{array}{l}\text { Label claim } \\
\text { (mg/10ml) }\end{array}$ & $\begin{array}{l}\text { Amount } \\
\text { added (\%) }\end{array}$ & $\begin{array}{l}\text { Total amount } \\
\text { of drug added }\end{array}$ & $\begin{array}{l}\text { Total amount of drug } \\
\text { obtained }\end{array}$ & \% Recovery \\
\hline \multirow{5}{*}{ Hexetidine } & 10 & 80 & 18 & 18.13 & 100.72 \\
\cline { 2 - 6 } & 10 & 80 & 18 & 17.98 & 99.88 \\
\cline { 2 - 6 } & 10 & 80 & 18 & 18.09 & 100.50 \\
\cline { 2 - 6 } & 10 & 100 & 20 & 20.05 & 100.25 \\
\cline { 2 - 6 } & 10 & 100 & 20 & 20.11 & 100.55 \\
\cline { 2 - 6 } & 10 & 100 & 20 & 19.99 & 99.95 \\
\cline { 2 - 6 } & 10 & 120 & 22 & 22.11 & 100.50 \\
\cline { 2 - 6 } & 10 & 120 & 22 & 21.97 & 99.86 \\
\hline
\end{tabular}

\section{Analysis of a formulation}

Experimental results of the amount of hexetidine in mouth wash formulations, expressed as a percentage of label claims were in good agreement with the label claims there by suggesting that there is no interference from any of the excipients which are normally present in formulation (Figure 6(a and b)).The drug content was found to be $100.99 \%$. Two different batches were analyzed using the proposed procedures.

\section{CONCLUSION}

A simple, rapid, less expensive, accurate, reliable HPTLC method has been developed for analysis of hexetidine as bulk drug and in pharmaceutical formulations without any interference from excipients. The data shows that the method is suitable for routine analysis of the drugs and drug formulations.

\section{Books:-}

\section{REFERENCES}

1. British pharmacopoeia, British Commission Office, British pharmacopoeia 2010, the Stationary office limited, London.

2. Merck index an encyclopedia of chemicals drugs and biological, $14^{\text {th }}$ edition, White House Station NJ, USA, 2006, p. 4703.

3. S. C. Sweetman. Martindale the complete drug reference, 31st edition, Pharmaceutical Press, London, 1989, p. 1134.2.

4. International Conference on Harmonization (ICH), Q2B: Text on Validation of Analytical Procedures: Definitions and Terminology, Vol.60. US FDA Federal Register, 1995.

\section{Literatures:-}

5. Determination of the salivary retention of hexetidine in-vivo by high-performance liquid chromatography. McCoy, C.P., Jones, D.S., McGovern, J.G., Gorman, S.P., Woolfson, A.D. J. Pharm. Pharmacol. (2000) August 1979, Volume 12, Issue 8, pp 530-532.

6. On-column interactions in the direct GLC assay of hexetidine. J. Traveset, V. Such, R. Gonzalo, E. Gelpí, chromatographia. 